\title{
REPORT OF A FAMILY SUFFERING FROM FRIEDREICH'S DISEASE, PERONEAL MUSCULAR ATROPHY, AND SCHIZOPHRENIA
}

\author{
By \\ MICHAEL SHEPHERD \\ From the Professorial Unit, the Maudsley Hospital, London
}

Despite the many clinical and pathological data which have accumulated about the heredo-familial ataxias, Gardner's comment on Friedreich's disease almost 50 years ago, that ". . . the chief point to bear in mind about its aetiology is the tendency it shows to run in families " (Gardner, 1906), remains true of the group today. In consequence, the knowledge to be derived from the investigation of family pedigrees assumes great importance in the study of these disorders.

Unfortunately for the purpose, the heredo-familial ataxias are relatively uncommon affections of the central nervous system. Kinnier Wilson (1940) could find no more than 73 cases of Friedreich's disease among all patients attending the National Hospital, Queen's Square, from 1909 to 1925, i.e., about 0.4\% of all admissions, and Sjögren was able to find only 188 cases in the records of six large Swedish clinics surveyed over at least 23 years (Sjögren, 1943). In her authoritative monograph on Friedreich's ataxia and spastic paraplegia, Julia Bell included a review of pedigrees in the world literature up till 1939 (Bell and Carmichael, 1939). She mustered 319 pedigrees in all, including 46 which were personally investigated ; of these 136 were of hereditary ataxia, 72 of spastic ataxia, 35 of hereditary and spastic ataxia combined, and 74 of spastic paraplegia, two being unclassified. Only 69 of these family trees, however, included five or more afflicted persons, and this limitation handicaps the study of the rich variety of abortive and intermediate forms of the clinical pictures encountered.

This paper presents an account of a large, hitherto unpublished pedigree of one family displaying a number of neurological variants. In addition, several members of the family suffered from psychiatric disabilities; the mental state of the propositus in particular was clearly schizophrenic and of considerable interest in view of the renewed attention which has recently been paid to the association between that mental illness and Friedreich's disease.

\section{Case Histories}

Case II 28.-A. B., a man aged 53, was transferred to the Maudsley Hospital in February, 1953, from a metropolitan observation ward where a diagnosis of schizophrenia had been made. One month before admission he had become worried at the prospect of his daughter's forthcoming parturition. He appeared depressed; he refused to go to work and behaved peculiarly, often talking incomprehensibly to objects in the room.

Personal History.- This was the third time the patient had been admitted to hospital on account of mental symptoms. Coming from a working-class, south-east London background he had led a quiet, otherwise uneventful life which, until the outbreak of World War II, had been clouded by unemployment. For the past decade he had been working for the L.C.C., recently as a lavatory attendant.

Medical History.-Medically he had been aware of a physical disability affecting his feet at the age of about 11 and had attended many clinics on this account. He had undergone several orthopaedic operations, including a Steindler operation, a removal of the navicular bone of the right foot, a tenotomy of the extensor tendons of the toes, a subtalar arthrodesis, and a wedge tarsectomy; in 1936 he had had multiple arthrodeses performed on all his toes. During his admission to hospital in 1936 for orthopaedic treatment he was examined neurologically and a diagnosis of Friedreich's disease was made, although this fact was not known at the time of his admission to the Maudsley Hospital in 1938.

Previous Mental Health.- $-\mathrm{He}$ was first admitted to the Maudsley Hospital in 1938 when he was referred from Guy's Hospital (Dr. R. D. Gillespie) as a case of schizophrenia. He complained at this time of constant auditory hallucinations ; two voices, those of a man and a woman, were with him all the time. He also felt that he was being " controlled" in some indefinable way and he was troubled by constant hissing in his ears. On the subject of his abnormal experiences and ideas the patient was noted to have rambled on indefinitely but in other spheres he was cooperative and rational and at all times retained clear consciousness. He was considered to have been slightly euphoric and to have demonstrated a minimal slurring of speech. In the central nervous system he was noted to have had absent knee and ankle 
jerks but no other physical signs were elicited. Bilateral pes cavus, however, was observed at the time. A diagnosis of general paralysis of the insane was mooted until a normal cerebrospinal fluid was obtained on lumbar puncture. Not one of the many doctors who saw him in 1938 questioned the diagnosis of schizophrenia after the result of this investigation.

He was known to have a wife and children at the time but the family history was said to be "negative". After two months in hospital the patient was discharged "cured". There had been a gradual recession of his ideas of influence and reference, and his auditory hallucinations had also disappeared. The only symptom of which he complained at the time of his discharge was a residual hissing in the ears. He was said to have acquired retrospective insight into the abnormal nature of his condition which he regarded as a strange experience and one which he could not explain. He resumed work and remained well for more than a year, but in 1939 was admitted to an observation ward for one week with a recurrence of symptoms. These quickly resolved in hospital and he was discharged home in October, 1939. He remained completely well according to his wife until January, 1953, spending most of the war period in London and standing up well to the inevitable stresses and strains of that time.

Physical State.-On examination, in February, 1953, the patient was a well built, middle-aged man who looked his age. He had a lugubrious expression and very mobile features. Physically he displayed bilateral pes cavus with an equinovarus deformity of both feet which bore the scars of several operations. The remaining physical signs were confined to the central nervous system. Examination of the cranial nerves revealed a bilateral coarse nystagmus most marked on ocular deviation to the right. A slight bilateral ptosis and a slurring dysarthria were also noted. The fundi were normal and no abnormality was detected in the remaining cranial nerves. In the limbs marked bilateral wasting of the musculature below the knees was observed; the intrinsic muscles of both hands were also wasted. There was marked weakness of all wasted muscle groups and the distal musculature of the limbs was weaker than normal. All four limbs were hypotonic. Coordination was impaired in the upper and lower extremities; the gait was ataxic ; there was a coarse intention tremor of both arms. Vibration sense was grossly impaired; there was impairment of position sense in the toes; there was relatively slight impairment of pain and touch sensation in the legs up to the knees. All deep tendon reflexes were abolished. The plantar reflexes were equivocal. While in hospital he was examined by two neurologists, one of whom was of the opinion that the patient's clinical picture resembled that of peroneal muscular atrophy rather than of Friedreich's disease, the other favouring the latter diagnosis. The existence of an hereditary neurological disorder stimulated an interest in the possibility of finding other cases and Fig. 1 represents the family pedigree obtained.

Mental State.-Mentally he presented a complex picture. No overt abnormality was apparent in his behaviour in the ward, and at interview he was quiet and cooperative, discussing neutral topics with equanimity. While discussing recent personal and emotionally charged events he became garrulous, displaying shortlived reactions which were often incongruously exaggerated, particularly in the direction of surprise, suspicion, or amusement ; he as quickly resumed his even tenor afterwards. He was always in full touch with his surroundings. His mood was mostly euphoric to the point of fatuity. He entertained a number of curious delusional ideas, many of them with a grandiose flavour : with these went constant auditory hallucinations to which he freely gave expression. His attitude to these

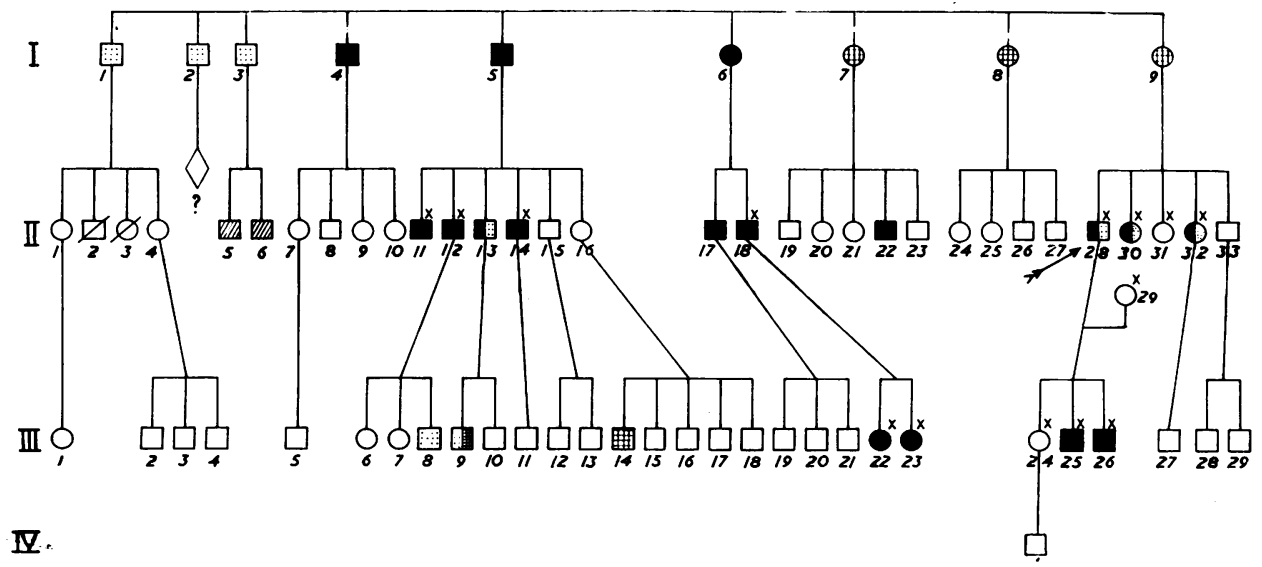

No evidence of physical or mental disease

Neurological disorder

Psychiatric disorder

Associated physical disorder

Unknown whether disease present or not

Personally examined 
abnormal ideas and experiences was at no time paranoid ; on the contrary he appeared to maintain a calm detachment when discussing them. Samples of his talk on admission illustrate these points :

" I may say that I could see, observe, and separate the spheres (or circular beads of fashion) but I am not in a position to know their names or functions. There was something else to look for which I possess and everyone possesses, the four spheres, the formation: the mind and three others. The mind shares the eyes, the outlook: one for each eye, one higher up in the forehead, keeping clearness of the skull, avoiding pain. Any of them can go adrift, if not tampered with, can be restored normally by the man suffering from these derangements, which are aggravated by the man's intentions... I think penetrating rays come through the walls, looking like white steam. They must have enough plates, negatives or positives or what you call them, to supply the world. The same two people I can hear that I heard here last time. I swear by that. A man with a low voice and woman with a sweet voice, with a sweet little voice that can lead you up the garden. The persuasive sort, the film actor, the woman and the man. I call her my Quiz or my Quizzie. Help her day and night; she must be in close touch with this hospital and they re company for me in my solitude, my friends with their little jokes ... I am not at all depressed but holy if I may say so. Godly and resigned. I call for assistance or help, give instructicns to all environments and functions concerning myself . ..."

By contrast there was no gross abnormality to be detected in his cognitive functions on clinical testing and no obvious thought disorder in the manner in which he answered routine questions. He was quite without insight into his illness and maintained that he was perfectly well at all times.

A number of special investigations were carried out. The blood Wassermann reaction was negative. The C.S.F. was normal. An E.E.G. was within normal limits. An electromyogram was normal. An E.C.G. showed left axis deviation. Dorsal kyphoscoliosis was demonstrated radiologically.

A number of psychological tests were administered. The full-scale Wechsler-Bellevue gave him an I.Q. of 89 (the verbal scale I.Q. was 88 and the performance scale I.Q. 93). A full and careful investigation of his thought disorder was undertaken. The outstanding features of this disorder were considered to be the concreteness, the bizarreness, and the tendency to clang associations. An attempt was made to discriminate between a schizophrenic thought disorder and a thought disorder consequent on brain damage. For this purpose the patient was given the Goldstein-Scherer sorting test, the Rorschach, the Nufferno speed and power test, the Babcock speed test, the U.S.E.S. manual and finger dexterity test, and the M.A.P.S. test : no conclusive evidence of either brain damage or of what is considered to be characteristic of schizophrenic thought disorder was obtained from these test batteries.

Progress.-During his three months in hospital the patient changed little. His general conduct was good, though occasionally he evinced phases of apparent obstinacy which were usually related to some delusional idea, e.g., he refused to shave because

". . I am, according to facial, my figure, my disabilities and my beard which I have let grow from this memory to be like Jesus Christ, who suffered from others as I have in my past. I wish to have His countenance."

He became quieter and refused to discuss his experiences and ideas with anyone except the medical staff. In consequence his wife and family considered him to be well enough to leave hospital and resume work. At the time of his discharge in May, 1953, however, he was still harbouring the same ideas and still experiencing the same hallucinations as at the time of his admission though he discussed them much less freely.

He resumed work at his old job. Seen as an outpatient six months after discharge, he admitted to hearing the same voices and the same hissing in his ears, but was less emphatic about his interpretations of these experiences. In July, 1954 (14 months after his discharge), he was readmitted to an observation ward on account of truculent behaviour and was subsequently sent to a mental hospital under certificate. His mental state was very similar to that described above.

Cases III 25 and III 26 are the children of the propositus.

Case III 25. - This man, aged 29, was seen and examined. He was noticed to have been suffering from bilateral pes cavus at the age of 3 ; he had difficulty with his feet at the age of 8 , when he attended hospital for physiotherapy and exercises until he was 13 years of age. Marked physical disability dates from the age of 17 . In 1953 he was seen by an orthopaedic surgeon on account of the deformity of his feet, and he was then referred for a neurological opinion, which was that the case " strongly suggested the diagnosis of the CharcotMarie-Tooth's type of muscular atrophy ". A radiograph of the spine taken at this time showed ". . . a marked mid-dorsal kyphosis involving most of the vertebrae, presumed Scheuermann's disease".

On examination this man was well developed physically but showed a kyphoscoliosis and a gross bilateral pes cavus with secondary callosities. In the central nervous system the cranial nerves were normal ; there was no nystagmus and the fundi were healthy. There was wasting and marked paresis of all muscle groups below the knee and some weakness of the thigh muscles. There was also weakness of the intrinsic hand muscles and of the wrist extensors, though there was no apparent wasting of these muscles. The tone and coordination of all muscle groups appeared normal. There was slight impairment of vibration sense, position sense, touch and temperature sensation below the knee. The deep reflexes of the upper extremities were intact; the ankle jerks were absent and the knee jerks diminished; plantar reflexes were equivocal.

Case $\amalg$ 26.-This boy, aged 15, was seen and examined. His only previous illness had been at the age of 3 years when he was admitted to hospital, first with a cellulitis and later with acute rheumatism. The hospital notes at that time made no mention of either foot 
deformity or central nervous disease. A high arch had been noticed by his parents for the first time one year before he was seen, i.e., at the age of 14 .

No obvious mental abnormality was detected at the interview. The patient was a well developed adolescent youth with a dorsal kyphosis and a bilateral pes cavus. No evidence of rheumatic sequelae could be detected in the heart. In the central nervous system the cranial nerves showed no abnormality except for a questionable dysarthria which could not be easily classified; the patient volunteered the information that many people had commented on his " funny "way of talking for some years. There was weakness of the extensor groups of leg muscles; no abnormality could be detected in the musculature of the arms. Muscle tone was normal but he had an ataxic gait with a positive Romberg's sign and an intention tremor of the right arm. There was impairment of position sense in the toes and the vibration sense in the lower extremities was diminished. Both the ankle jerks were absent ; the remaining deep tendon jerks were present and equal; the plantar reflexes were equivocal.

Cases II 30 and II 32 are sisters of the propositus.

Case II 30.-This woman, aged 56, was seen and examined. She was an odd personality, who admitted to being "very nervy". A spinster, she had lived alone for many years meeting hardly anyone except for a few members of her immediate family. She had suffered from foot trouble since childhood and had become increasingly disabled during the past decade. She had a marked bilateral pes cavus. On examination of the central nervous system the cranial nerves showed no abnormality though she spoke with a curious nasal intonation. There was weakness of the extensor muscles of toes and ankles but her most marked motor disability was in the small muscles of the hands, which displayed a considerable degree of atrophy. There was consequent weakness of the intrinsic hand muscles and weakness was also noted in the extensor muscles of the wrists. Tone and coordination of the extremities appeared normal. Position sense in the toes was impaired. Ankle jerks were absent ; the knee jerks were depressed ; the deep tendon reflexes of the arms appeared normal ; the plantar responses were equivocal.

Case II 32.-The second sister, aged 49, was seen and examined. She admitted to having been a "nervous woman" for many years. At the age of 24 she suffered a " nervous breakdown" following her father's death : she was off work for six weeks and stated that she had lost her memory for some days. She had been subject to depressive episodes all her life in which she had displayed self-reproach and had occasionally entertained suicidal thoughts. She considered herself to be free of the familial disease, of the existence of which she was aware. On examination she appeared somewhat despondent but displayed no gross psychiatric abnormality. In the central nervous system no abnormality could be detected other than a pronounced bilateral pes cavus without secondary deformities.

The remaining cases are all more distant maternal relatives of the propositus.
Case I 1.-A male, died, aged 56, in a mental hospital. He was diagnosed as a case of G.P.I. and at necropsy the immediate cause of death was identified as aortic aneurysm. He was also suffering from arteriosclerosis. The Wassermann reaction in the C.S.F. was strongly positive and a paretic Lange curve had been reported shortly before his death. He had been known to be suffering from tabes dorsalis in 1916 and on admission to hospital the positive findings included Argyll Robertson pupils, a tremor of the hands, grandiose delusions, and absent deep tendon and abdominal reflexes.

Case I 2.-This case was a male who died in a mental hospital aged 42. The statutory documents pertaining to this case were examined by permission of the Medical Superintendent of the mental hospital concerned. The patient was admitted under certificate to a mental hospital for the first time in January, 1904, and died there six months later of tuberculous disease of the lungs and intestines which was considered to have been present before admission (information from postmortem report). His mental illness was said to have begun two months before admission and to have been related possibly to "blindness and an operation to his head"; no further information about either of these circumstances was available. On admission he was considered in the certificate of the medical practitioner to be

"suffering from delusional insanity, he imagines he can hear his mother talking to him, also other voices, says he has money in the bank, besides a business of his own, he only comes in here to sponge on the ratepayers, if he is kept longer than he wishes he will smash all the windows".

Further imformation was added :

" He is very noisy, complains of being kept in and would sooner be in hell, threatens to break all the windows and is very abusive towards the other patients. He does not sleep at night and carries on a conversation with imaginary people, and makes use of very obscene language."

Case I 3.-Male, died aged $50+$. Known to have been a drunkard for many years.

Case I 4.- Male, died aged 70+. Known to have - suffered from trouble with his hands and feet for many years.

Case I 5. - Male, died aged 50+. Known to have suffered from foot deformity and asthma and to have been " round-shouldered" all his life. His son (Case II 11 says that his own present state is exactly the same as his father's shortly before death.

Case I 6.-Female, died aged 82 in 1950 of " natural bronchial pneumonia, hyperpiesis, and arthritis" (death certificate). According to the evidence of her son she was " nervy" all her life and suffered from bilateral pes cavus during her adult life.

Case I 7.-Female who died of cardiac disease aged $60+$.

Case I 8.-Female who died of cardiac trouble aged $70+$. 
Case I. 9.-Female who died of cardiac disease aged 63. She was not afflicted with any abnormality of the central nervous system.

Case II 11.-This man, aged 64, was seen and examined. He was in an advanced stage of the illness when seen but was able to give a clear account of its development. He stated that he first began to "fall" at the age of 8 . His foot trouble had become increasingly disabling but not until he was about 39 years of age did he develop trouble with his hands. During the past decade his work had suffered and he was at the time of examination almost crippled with his disabilities. On examination he evinced numerous involuntary movements of the limbs and face and he had an obvious kyphosis of the dorsal spine. He showed bilateral club feet with scars of numerous old operations and multiple callosities on the plantar surfaces. He stated that when he first went to hospital in his 20 s he was told that he had " no knee jerks". In the central nervous system he had very small pupils but otherwise the cranial nerves were intact. There was wasting and weakness of the distal musculature of both lower extremities and in addition both the hands showed gross wasting and weakness of the intrinsic muscles and the wrist extensors were also wasted and paretic. There was no tremor of the outstretched arms. Considerable muscular fasciculation was observed in the distal musculature of arms and legs. There was some impairment of the postural and vibration sense of the legs below the knees. No deep reflexes could be obtained in the limbs and the plantar responses were equivocal.

Case II 12.--This man, aged 52 , was seen and examined. He was an active wcrking man in spite of a bilateral pes cavus with secondary deformity; the left foot was more severely affected than the right. No abnormality could be detected in either the cranial nerves or in the modalities of power and tone in the limbs. The only sensory abnormality was impaired vibration sensation below the knees in both legs. The deep tendon reflexes were present and equal in all four extremities. This patient also suffered from a left bronchiectasis for which he had been receiving hospital treatment.

Case II 13. - This man, aged 50, was seen, but refused examination. He was regarded by his brothers as an "odd fish" who had little to do with other members of his family. When seen with the psychiatric social worker he was resistive to the point of aggression and refused all blandishments and attempts to persuade him to undergo examination. He admitted however that his feet had been deformed ever since he could remember and had been the cause of many years of misery. It was obvious that he suffered from gross wasting of the intrinsic muscles of the hands. The irritable, peevish, almost paranoid attitude displayed at interview was, according to other informants, characteristic of this man.

Case II 14. - This man, aged 40, was seen and examined. A bilateral pes cavus, more marked on the left than on the right, was the only abnormality detected.

Case II 17.-This case was a male aged $40+$, but was not seen. He was stated by a reliable witness (brother) to have suffered from a "tremor of his hands" since childhood. No definite information about his feet was forthcoming.

Case II 18. - A man, aged 42, was seen and examined. He was a physically well developed workman of good average intelligence. He claimed to have been " nervy" all his life. On examination he showed a pronounced dorsal kyphosis. He had marked bilateral pes cavus with no obvious wasting. Nothing abnormal was detected in the cranial nerves. Power and tone of all four limbs were normal but the patient evinced a marked tremor of the outstretched hands and an intention tremor which he said had been present for as long as he could remember. Vibration sense was absent up to the ankle ; there were no other sensory abnormalities detected. Knee and ankle jerks were absent ; the remaining deep reflexes were present and equal; plantar reflexes were flexor.

Case III 9.-A male, aged 24, was not seen. Information from his father revealed that this boy had been invalided from the army on psychiatric grounds. $\mathrm{He}$ also suffered from diabetes mellitus. He had apparently been a difficult person to manage for many years but no further information could be obtained.

Case III 14. - A male, aged $20+$, was not seen. He was known to suffer from diabetes mellitus.

Case III 22.-This girl, aged 13, was seen and examined. She had been referred one month before examination to an orthopaedic clinic on account of weakness of the ankles. The orthopaedic report was to the effect that she was suffering from a postural defect which could be remedied by exercises. On examination she proved to have a bilateral pes cavus with absent knee and ankle jerks ; the other deep tendon reflexes were present and equal and the plantar reflexes were flexor. No other abnormality was detected in the central nervous system apart from a fine tremor of the outstretched hands and an intention tremor in the upper extremities.

Case III 23.-A girl, aged 10, was seen and examined. This child was apparently asymptomatic but on examination she was shown to have a bilateral pes cavus with absent knee and ankle tendon reflexes. No other abnormality was detected in the central nervous system.

\section{General Commentary on the Family}

In summary, reliable clinical information was gathered about 72 members of one family of whom 17 people certainly suffered from some form of inherited neurological disease and a further four from associated physical illnesses. The psychiatric aspects of the case material will be discussed later. There may be merely enumerated at this stage the schizophrenic illness of the propositus, the depressive illness of his sister (Case II 32), the abnormal personalities of another sister, a cousin, and an uncle (Cases II 30, II 13, and I 3), the mental illnesses of the two maternal uncles who died in mental hospitals (Cases I 1 and I 2), and the presumptive psychopathy of his nephew (Case III 9). 
It is true, as Hogben (1934) has pointed out, that " Single pedigrees may suggest the lines along which scientific interpretation is to be sought. They cannot in general provide conclusive evidence." Nevertheless, the findings raise a number of genetic, neurological, and psychiatric issues which are still sufficiently obscure to warrant brief discussion.

\section{Discussion}

Neurological.-Neurological stigmata were exhibited by both sexes. Twelve out of 28 males and five out of 23 females were affected, the preponderance of males in the family being to some extent responsible for the larger number of male patients recorded.

The earliest symptom of the disorder in either sex was invariably some form of "foot trouble" which made its appearance in childhood. In this connexion Case III 22 is of particular interest, for the patient, a girl aged 13, was seen and examined only a few weeks after her first visit to an orthopaedic clinic with a complaint of "foot trouble"; at the same time her younger sister, aged 10, already displayed evidence of the disease although she was asymptomatic at the time of examination.

Where several collaterals showed neurological symptoms the older members appeared to suffer more severely. This tendency was most clearly illustrated in the case series II 11 to II 16 , for the two oldest siblings had been compelled to abandon work in the sixth decade whereas the two youngest were unaffected. The same trend may be witnessed in the case series II 28 to II 33, of which the propositus is the oldest member. It may also be noted that, as far as could be ascertained, life was not appreciably shortened by the disease process among even the most severely crippled ; thus the propositus had had symptoms for at least 42 years, Case II 11 for 56 years, while in no case was it possible to incriminate the disease process as a proximate cause of death.

The form and the severity of the neurological disorder were inconstant in the family. Its least noxious expression was observed in Cases II 14 and II 32, whose bilateral pes cavus constituted the one detectable physical sign. Whereas the lower extremities were invariably and sometimes uniquely affected, the disease process went on to involve the upper extremities of the propositus and of Cases II 11 and II 30. Wasting of the affected musculature was a striking feature in these cases and it is noteworthy that in hospital the propositus was labelled a case of Friedreich's disease by one neurologist but was thought to be suffering from Charcot-MarieTooth's disease by another, despite the ataxia, dysarthria, nystagmus, and kyphosis. Further, one of his sons had already been given the latter diagnosis, while the other son showed many of the classical signs of Friedreich's disease. The close relationship existing between Friedreich's disease and peroneal muscular atrophy has been well attested by the several cases and family trees in which both conditions occur (Greenfield, 1911-12 ; Biemond, 1928 ; Spillane, 1940). However, the majority of affected cases in this family demonstrated additional evidence of the more widespread lesions characteristic of the several clinical patterns of Friedreich's disease, e.g., the frequently encountered pes cavus with absent or diminished knee jerks, the motor incoordination (Cases II 18, III 22, III 23), the nystagmus (Case II 28), the dysarthria (Case III 26), and the spinal deformities (Cases III 25 and 26 and II 11 and 18). Of the better recognized physical associations of Friedreich's disease diabetes mellitus was reported in Cases III 9 and III 14 and heart disease was known to have afflicted Cases I 7 , I 8, and I 9.

This prolixity of clinical variants can be best elucidated by reference to the intermediate and abortive forms of the heredo-familial ataxias which, as Roth has shown, require a genetic framework for their full understanding (Roth, 1948). The genetics of these disorders are complex and have not yet been worked out in their entirety. The necessity for postulating more than one Mendelian factor to account satisfactorily for the mode of transmission of Friedreich's ataxia, about which most is known, was early suggested by Brain (1925). From the evidence of her pooled case material Bell was enabled to demonstrate the close genetic links between Friedreich's disease, spastic ataxia, and spastic paraplegia, each of which claimed a dominant and a recessive type of inheritance. It appears probable that a sex-linked variant of all these conditions also occurs, and Haldane has speculated on the possibility of the existence of allelomorphic subdivisions existing within the three clinical conditions (Haldane, 1941).

It may be observed from the present family tree that the neurological abnormality was inherited as an irregular, autosomal dominant. This form of transmission is most unusual in recorded pedigrees of Friedreich's disease. Thus in Sjögren's experience all patients with Friedreich's disease exhibited a recessive form of inheritance. Bell and Carmichael comment specifically on their failure to meet with a single case of Friedreich's disease " . . . which was demonstrably of dominant genetic type " out of the 46 families they examined, and they went on to state that such cases were rare in the pooled material. It seems reasonable to suggest that the 
number of clinical differences discerned is directly related to the less common but more pleiomorphic dominant gene; and it is of interest that the families adduced by Spillane and by Roth as a basis for discussion of the intermediate forms of hereditary ataxia all displayed the dominant mode of trans. mission. The evidence to be derived from the present family thus further supports the case made by these authors for the discarding of rigid clinical syndromes within the group of disorders, and illustrates Kinnier Wilson's comment that " . . . by easy steps the Friedreich syndrome may move toward muscular dystrophies, spinal amyotrophies, spinal paraplegias, cerebellar or cerebral states " (Kinnier Wilson, 1940).

Psychiatric.-The mental changes associated with the heredo-familial ataxias, and in particular with Friedreich's disease, have received much less attention than the physical manifestations of these disorders. Most observations by neurologists have been focused on the impairment of cognitive ability to the neglect of the more complex mental functions, which are characteristically dismissed by Kinnier Wilson as ". . . instances of feeble-mindedness, mental debility, or worse ". The co-existence of psychotic illnesses with Friedreich's disease has for long been recognized by Continental workers, however, and many different abnormal mental states have been described, usually in isolated cases. After fully reviewing the relevant literature Davies" conclusion was that ". . . the relationship of the mental and neurological disorders is more fundamental than fortuitous ", although the nature of this relationship remains complex and obscure (Davies, 1947).

In the family under discussion several examples of mental abnormality were noted, most of them with but some without concomitant neurological disease. Of the former group the propositus presented a clear picture of schizophrenia, a diagnosis which had been made by a number of competent observers unaware of the nature of the neurological condition. The sister of the propositus, whose only neurological signs were those of a pes cavus and absent ankle jerks, suffered mild, recurrent depressive illnesses. Abnormal personality traits were observed in Cases II 13 and II 30 and their presence was corroborated by other witnesses; both patients were suffering from an advanced degree of neurological disability but not more than Cases II 11 and ]1 12, which showed no evidence of mental disturbance. These cases were personally seen and examined. The clearly described alcoholic and psychopathic features of Cases I 3 and III 9 indicated abnormal personality traits without neurological disease. The mental symptoms of Case I 1 must be regarded as dependent on his G.P.I., though it may be noted that he had previously been thought to suffer from tabes dorsalis, a diagnosis which has often been confused with that of Friedreich's disease. Lastly, the interesting mental illness of Case I 2, characterized by prominent delusional ideas and auditory hallucinations, appears to have been unassociated with neurological signs or symptoms.

It is not proposed here to discuss at length the general issue of the association between Friedreich's disease and the variegated forms of mental abnormality demonstrated by the family under consideration. Insufficient knowledge is available about the background and genesis of many of the psychiatric states observed and recorded. Attention is more profitably focused on the propositus, about whose schizophrenic illness extensive data were acquired.

The majority of recorded psychoses accompanying Friedreich's disease are of paranoid or frankly schizophrenic type, often with hallucinations, and the coincidence has provoked much interest in the past. The combination was striking enough to lead Kleist 30 years ago to speculate on the possibility of schizophrenia being a form of system-degeneration analogous to that postulated for the heredofamilial disorders (Kleist, 1923). At about the same time Lewis (1925) was led by similar considerations to regard the schizophrenic constitution as "... an heredo-degeneration whose localization was not at the higher neurogenic levels, but consisted of a defective factor outside the neuroectoderm with the primary focus located in those primitive cells the later differentiation of which produces the mesodermal and entodermal structures ". Conversely, in the opinion of de Smedt and others, the psychiatric and neurological conditions are genetically distinct even when clinically associated, a point of view which has been adopted by several other workers in the field (Smedt, Wulf, Dyckmans, and van Bogaert, 1937). An intermediate view is discussed by Birkmayer and Lenz in relation to their patients who suffered from both disorders and came from a family with mental illness on the paternal side and neurological disease on the maternal side : they admit the possibility of a mutual reinforcement of genetic factors in a non-Mendelian fashion, bringing about a more pronounced clinical picture in predisposed cases (Birkmayer and Lenz, 1939). Unfortunately for the testing of this latter hypothesis, the family history of the propositus was obtainable in the present instance on only the maternal side, though no knowledge of paternal illness was vouchsafed by the numerous informants. There may, therefore, be more genetic significance in the mental illness recorded of the patient's 
maternal uncle (Case I 2) which is compatible with a schizophrenic reaction. It remains unclear why the propositus alone exhibited the admixture of schizophrenic and neurological symptoms.

The most recent attempt to explain the association between Friedreich's disease and the psychoses encountered with it has been propounded by Bleuler and Walder (1946). According to them, the mental state in Friedreich's disease exemplifies the so-called psycho-organic syndrome (Bleuler, 1951), and is closely akin to that witnessed in the psychoses associated with epilepsy which the authors consider to be due to diffuse, slowly developing brain damage; they point to the mild dementia, the egocentricity, the euphoric mood, and the delusional ideas and hallucinations with a religious content as evidence of the symptoms common to both conditions. Their view has been upheld by several Continental workers (Blöchlinger, 1946; Schneider, 1946; Knoepfel and Macken, 1947) and it is worth noting that only one case history was included in their original paper, that of a 53-year-old woman whose neurological symptoms dated from childhood and had become incapacitating by the age of 33 . Her mental state was thought to be indistinguishable from that seen in a psychosis associated with epilepsy. As a single case the propositus bears close comparison to Bleuler's patient in respect of age, the early onset of neurological symptoms, and the relatively late appearance of very similar mental symptoms which included delusional ideas and hallucinatory experiences with a religious content. However, detailed clinical and psychological examination (the tests employed being far more refined than those used by Bleuler) failed to show any evidence of brain damage. Further, the E.E.G. yielded no support for the diagnosis of epilepsy.

The whole concept of the Friedreich psychosis as an example of the psycho-organic syndrome has been assailed by Davies principally on the ground that there is no satisfactory pathological evidence of diffuse cerebral changes in Friedreich's disease (Davies, 1949). The suggestive features of individual cases he accounts for in terms of the uncommon but established association of epilepsy with Friedreich's ataxia along with the secondary effects of chronic invalidism. The case history of the propositus further illustrates the difficulty imposed by over-simplification, since epilepsy and dementia can be definitely excluded in spite of a clinical picture which would have qualified in most respects for inclusion among the cases chosen to exemplify Bleuler's syndrome. The existence of the several other and variegated psychiatric conditions described in the family also poses questions which cannot be answered in terms of the psycho-organic hypothesis alone.

The psychiatric disorders associated with Friedreich's disease would seem, therefore, to demand a broader approach for their elucidation. The known genetic factors influencing the transmission of the heredo-familial diseases constitute an obvious field of enquiry, complementary to the clinical observation of individual cases. However, as the present pedigree clearly indicates, it will be necessary for this purpose to accumulate and study both family pedigrees and individual cases which have been as well investigated from the psychiatric as from the neurological points of view.

\section{Summary}

A family has been described in which 17 members exhibited various forms of heredo-familial ataxia. The clinical and genetic aspects of the neurological disorders have been discussed.

In addition, the propositus was suffering from a schizophrenic illness and six more members were traced with psychiatric histories of different types.

The possible relationships between heredofamilial ataxia and schizophrenia have been discussed. Further doubt has been cast on the concept of the psycho-organic syndrome as applied to this association.

I should like to acknowledge the invaluable assistance afforded by the psychiatric social worker, Mr. Edgar Myers, without whose diligence and pertinacity many? members of the family tree could not have been traced. I am also indebted to Dr. Eliot Slater for his suggestions and advice.

\section{REFERENCES}

Bell, J., and Carmichael, E. A. (1939). Hereditary Ataxia and Spastic Paraplegia. The Treasury of Human Inheritance, vol. IV, pt. III. Cambridge University Press, London.

pt. III. Cambridge University Press, London.

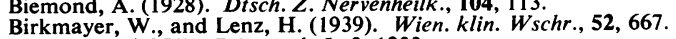

Bleuler, M. (1951). Brit. med. J., 2, 1233.

, and Walder, H. (1946). 'Schweiz. Arch. Neurol. Psychiat., $58,44$.

Blöchlinger, K. A. (1946). Die psychischen Störungen bei der Friedreichschen Ataxie. Inaugural Dissertation, University of Zurich.

Brain, W. R. (1925), Quart. J. Med., 18, 351.

Brain, W. R. (1925), Quart. J. Med., 18, 351 .
Davies, D. L. (1947). Psychiatric Changes in Friedreich's Ataxia. Thesis, Oxford.

(1949). Journal of Neurology, Neurosurgery and Psychiatry, 12,34 and 246.

Gardner, E. (1906). Brain, 29, 112.

Greenfield, J. G. (1911-12). Proc. roy. Soc. Med., 5, Neurol. Sect.,

p. 75.
Haldane, J. B. (1941). New Paths in Genetics, p. 187. Allen and Unwin, London.

Hogben, L. (1934). The Analysis of Pedigrees. Appendix to The Chances of Morbid Inheritance, ed. C. P. Blacker. Lewis, London.

Kleist (1923). Klin. Wschr., 2, 962.

Knoepfel, H. K., and Macken, J. (1947). J. belge Neurol. Psychiat., 47, 314.

Lewis, N. D. C. (1925). J. nerv. ment. Dis., 62, 225.

Lewis, N. D. C. (1925). J. nerv. men,

Schneider, G. (1946). Schweiz. Arch. Neurol. Psychiat., 58, 145.

Sjögren, T. (1943). Acta psychiat., Kbh., Suppl. 27.

Smedt, E. de, Wulf, A. de, Dyckmans, and Bogaert, L. van. (1937). J. belge Neurol. Psychiat., 37, 155.

Spillane, J. D. (1940). Brain, 63, 275.

Wilson, S. A. K. (1940). Neurology. Arnold, London. 